\title{
Intravenous pamidronate in the treatment of osteoporosis associated with corticosteroid dependent lung disease: an open pilot study
}

\author{
University \\ Department of \\ Medicine \\ S J Gallacher \\ J A K Fenner \\ I T Boyle \\ Department of \\ Respiratory Medicine \\ $\mathrm{K}$ Anderson \\ S W Banham \\ Department of \\ Radiology \\ F M Bryden \\ Institute of \\ Biochemistry \\ FC Logue \\ RA Cowan \\ Glasgow Royal \\ Infirmary, Glasgow \\ G31 2ER \\ Reprint requests to: \\ Dr Gallacher \\ Received 15 January 1992 \\ Returned to authors \\ 31 March 1992 \\ Revised version received \\ 27 April 1992 \\ Accepted 7 May 1992
}

Stephen J Gallacher, J A Kathryn Fenner, Kenneth Anderson, Fiona M Bryden, Stephen W Banham, Fraser C Logue, Robert A Cowan, Iain T Boyle

\begin{abstract}
Background Bisphosphonates have been shown to be effective agents in the treatment of postmenopausal osteoporosis. Because corticosteroid associated osteoporosis is often associated with increased bone turnover, the effect of intermittent intravenous infusions of pamidronate on this condition has been investigated.
\end{abstract}

Methods Seventeen patients (five male) with chronic corticosteroid dependent lung disease (15 asthma, two sarcoidosis) were treated with infusions of $30 \mathrm{mg}$ pamidronate once every three months for one year. These patients had been taking an average of 14 (range $7 \cdot 5-40$ ) $\mathrm{mg}$ prednisolone a day for an average of 14 (range 3-30) years. Bone density measurements, by dual energy $x$ ray absorptiometry, and radiography of the dorsolumbar spine were carried out before and one year after treatment. Bone formation was assessed by measurement of serum alkaline phosphatase and bone resorption by measurement of the fasting urinary hydroxyproline : creatinine ratio at the same time as densitometry and radiography were performed.

Results Pretreatment density of L2-4 and the neck of the femur was significantly lower in these patients compared with a cohort of 100 age and sex matched controls (L2-4 (mean (SEM)): 0.906 (0.050) g/ $\mathrm{cm}^{2} v 1.142(0.016) \mathrm{g} / \mathrm{cm}^{2}$; neck of femur: $\left.0.793(0.030) \mathrm{g} / \mathrm{cm}^{2} v 0.936(0.013)\right) \mathrm{g} / \mathrm{cm}^{2}$. After treatment there was a significant fall in serum alkaline phosphatase activity from (mean (SEM)) 220 (16) U/1 to 174 (9) $U / 1$ (normal 80-280 $U / 1$ ) and in the fasting urinary hydroxyproline:creatinine ratio from (mean $\begin{array}{llllll}(S E M) & 0.040 & (0.006) & \text { to } & 0.024 & (0.003)\end{array}$ (normal $<0.033$ ). A significant rise was noted in L2-4 density to $0.927(0.047) \mathrm{g} /$ $\mathrm{cm}^{2}$; mean rise of $3.4 \%$ ). No change was noted in density of the neck of the femur. Conclusions Intermittent infusions of intravenous pamidronate would seem to be effective in both reducing turnover of bone and increasing bone density in corticosteroid induced osteoporosis associated with chronic lung disease. Longer term controlled studies are indicated.

(Thorax 1992;47:932-936)
The use of long term oral corticosteroids in the treatment of asthma has been known for many years to be associated with osteopenia and an increased incidence of fractures. ${ }^{1}$

The pathogenesis of corticosteroid associated osteoporosis is complex, involving decreased intestinal calcium absorption, ${ }^{2}$ impaired gonadotrophin secretion, ${ }^{3}$ secondary hyperparathyroidism, ${ }^{4}$ and possibly altered metabolism of vitamin D. ${ }^{5}$ Furthermore, corticosteroids have direct actions on bone; increased bone resorption ${ }^{6}$ and decreased bone formation $^{7}$ under the influence of corticosteroids are well described.

Bisphosphonates are potent inhibitors of bone resorption ${ }^{8}$ and have been successfully used for some years in the treatment of the increased resorption of bone found with cancer associated hypercalcaemia ${ }^{9}$ and Paget's disease of bone. ${ }^{10}$ More recently bisphosphonates have been shown to be useful in the treatment of postmenopausal osteoporosis. ${ }^{112}$ Because corticosteroid associated osteoporosis is usually accompanied by increased bone resorption, we have investigated the use of intermittent intravenous infusions of the potent second generation bisphosphonate pamidronate in the management of this condition.

\section{Patients and methods}

PATIENTS

Patients were recruited from the chest clinics at Glasgow Royal Infirmary and associated hospitals. They all presented consecutively for routine review. Patients were included who had been taking an average minimum of $7.5 \mathrm{mg}$ prednisolone (or equivalent) a day for a minimum of two years, irrespective of whether or not they were thought to have appreciable osteoporosis. No relevant changes in dose of oral corticosteroid administered to these patients were noted during the year of treatment. Patients were excluded if they were undergoing any other treatment or had any other medical condition thought likely to interfere with their bone metabolism. Patients with a history of excessive ingestion of alcohol were also excluded. Twenty patients were recruited; one died (from respiratory failure) after only one infusion of pamidronate, one moved away from Glasgow, and one defaulted from further follow up after only one infusion. Results at one year of follow up, therefore, were available in 17 patients - 15 with asthma and two with sarcoidosis. The two patients with sarcoidosis had had consistently normal 1,25 dihydroxy- 
vitamin $\mathrm{D} 3(1,25(\mathrm{OH})$ 2D3) concentrations and were normocalcaemic. The table shows details of the patients. They were treated with $30 \mathrm{mg}$ pamidronate given as an intravenous infusion in $500 \mathrm{ml}$ isotonic saline over four hours once every three months. The first infusion was given when they were inpatients for noting side effects. At the time of review each patient had received five infusions (a total of $150 \mathrm{mg}$ pamidronate). An assessment of each patient's dietary calcium intake was made before treatment. In five patients this was considered likely to be less than $1000 \mathrm{mg}$ a day and in each case one sandocal 400 tablet twice daily was prescribed; otherwise no formal calcium supplementation was given.

\section{BIOCHEMISTRY}

Measurement of serum alkaline phosphatase (ALP) was made on each occasion by standard autoanalyser methodology as a marker of bone formation (normal range $80-280 \mathrm{U} / \mathrm{l}) .^{13}$ Similarly, a true fasting (second voided) urine sample was obtained for measurement of the hydroxyproline:creatinine ratio as a marker of bone resorption (normal <0.033). ${ }^{13}$ Hydroxyproline was measured by autoanalyser after resin catalysed hydrolysis ${ }^{14}$ and creatinine by autoanalyser. Intact parathyroid hormone was measured by a two site immunoradiometric assay, ${ }^{15} 25$-hydroxyitamin $\mathrm{D}(25(\mathrm{OH}) \mathrm{D} 3)$ by a competitive protein binding assay, and 1,25 $(\mathrm{OH}) 2 \mathrm{D} 3$ by radioreceptor assay. ${ }^{16}$

\section{DENSITOMETRY}

Spinal (L2-4) density and density of the neck of the femur were measured before and after one year of treatment by dual energy $x$ ray absorptiometry (DEXA; Lunar DPX). In our laboratory this has a precision, in normal subjects, of $0.9 \%(\mathrm{~L} 2-4)$ and $1.05 \%$ (neck of the femur). These are similar to the results obtained by others. ${ }^{17}$ All measurements were carried out on the same machine by the same operator and were analysed with the same software. Results were expressed both in absolute values as area densities $\left(\mathrm{g} / \mathrm{cm}^{2}\right)$ and also as the percentage change after treatment. Bone densities before treatment were compared with those of a cohort of 100 normal age and sex matched volunteers. These subjects had all been recruited through a local advertising campaign into a longitudinal study designed to monitor long term changes in bone

Clinical and biochemical details of the patients before treatment

No of patients

Age (years)

Prednisolone dose (mg/day)

Duration of treatment $(y)$

Time post menopause (y)

No of vertebral fractures before treatment

Parathyroid hormone (pmol/l) before treatment

SEM (range) (normal 1-5 pmol/l)

25(OH)D3 (nmol/1) before treatment

SEM (range) (normal 15-100 nmol/l)

$1,25(\mathrm{OH}) 2 \mathrm{D} 3(\mathrm{pmol} / \mathrm{l})$ before treatment

SEM (range) (normal 20-120 pmol/l)

Values are mean, SEM, and range.

*Five men, three premenopausal women, nine postmenopausal women. (median age 52, range 33-71 years), and 20 men (median age 38, range 29-57 years). They were all apparently healthy and did not have any condition or take any medication thought likely to interfere with their bone metabolism. Radiography was not carried out on this group.

\section{RADIOLOGY}

Plain radiographs of the dorsolumbar spine were obtained before and after one year of treatment. These were assessed by an experienced radiologist (FMB) and graded into normal, wedge deformity, biconcavity deformity, and compression deformity. Each category was further classified as grade 1 or grade 2 depending on the degree of deformity present. The radiologist reviewing the $x$ ray films was unaware of when they were taken in relation to the administration of pamidronate.

\section{STATISTICS}

Statistical comparison of data obtained before and after treatment was carried out with a two tailed paired Student's $t$ test. Comparison of bone density before treatment with that of normal controls was carried out with an unpaired $t$ test and correlations between ALP and hydroxyproline : creatine ratios were studied with the Spearman rank correlation test.

Approval for this study was obtained from the local hospital ethics committee and informed consent was obtained from all patients.

\section{Results}

A total of $82 \%$ of patients included in this study had previously sustained at least one vertebral compression fracture on the basis of plain radiology. Bone densities of L2-4 and the neck of the femur (mean (SEM)) were significantly lower than that in a cohort of normal age and sex matched control subjects (L2-4: 0.906 $(0.050) \mathrm{g} / \mathrm{cm}^{2}$ (steroid patients) $v 1.142(0.016)$ $\mathrm{g} / \mathrm{cm}^{2}$ (controls); p $<0.0005$. Neck of the femur: $0.793(0.030) \mathrm{g} / \mathrm{cm}^{2}$ (steroid patients) $v$ $0.936(0.013) \mathrm{g} / \mathrm{cm}^{2}$ (controls); $\mathrm{p}<0.00001$ ). Thus these patients had evidence of appreciable osteoporosis.

After one year of treatment there was a significant rise in L2-4 density to $0.927(0.047)$ $\mathrm{g} / \mathrm{cm}^{2}, \mathrm{p}<0.05$. This represents a mean increase of $3.4 \%(95 \%$ confidence interval $(95 \%$ CI $1 \cdot 1 \%$ to $5 \cdot 2 \%$; fig 1 ). After treatment density of the neck of the femur was 0.748 $(0.025) \mathrm{g} / \mathrm{cm}^{2}$, which represents a mean change of $1.8 \%(95 \%$ CI $-2.0 \%$ to $2 \cdot 3 \%$; fig 2$)$. In three instances L2-4 density decreased over the year of treatment and in one case no change was noted. In each of these instances bone densities before treatment were comparatively normal and were all greater than $1.000 \mathrm{~g} / \mathrm{cm}^{2}$. Those patients who responded best to treatment tended to have the lowest bone densities before treatment.

Radiologically one patient had a new wedge fracture at D9 and three patients showed progression of wedging of three individual vertebrae. 
Figure 1 Changes in L24 density with treatment (expressed as a percentage of pretreatment value). Bar represents $95 \%$ confidence interval.

Figure 2 Changes in density of the neck of the femur with treatment (expressed as a percentage of pretreatment value). Bar represents $95 \%$ confidence interval.
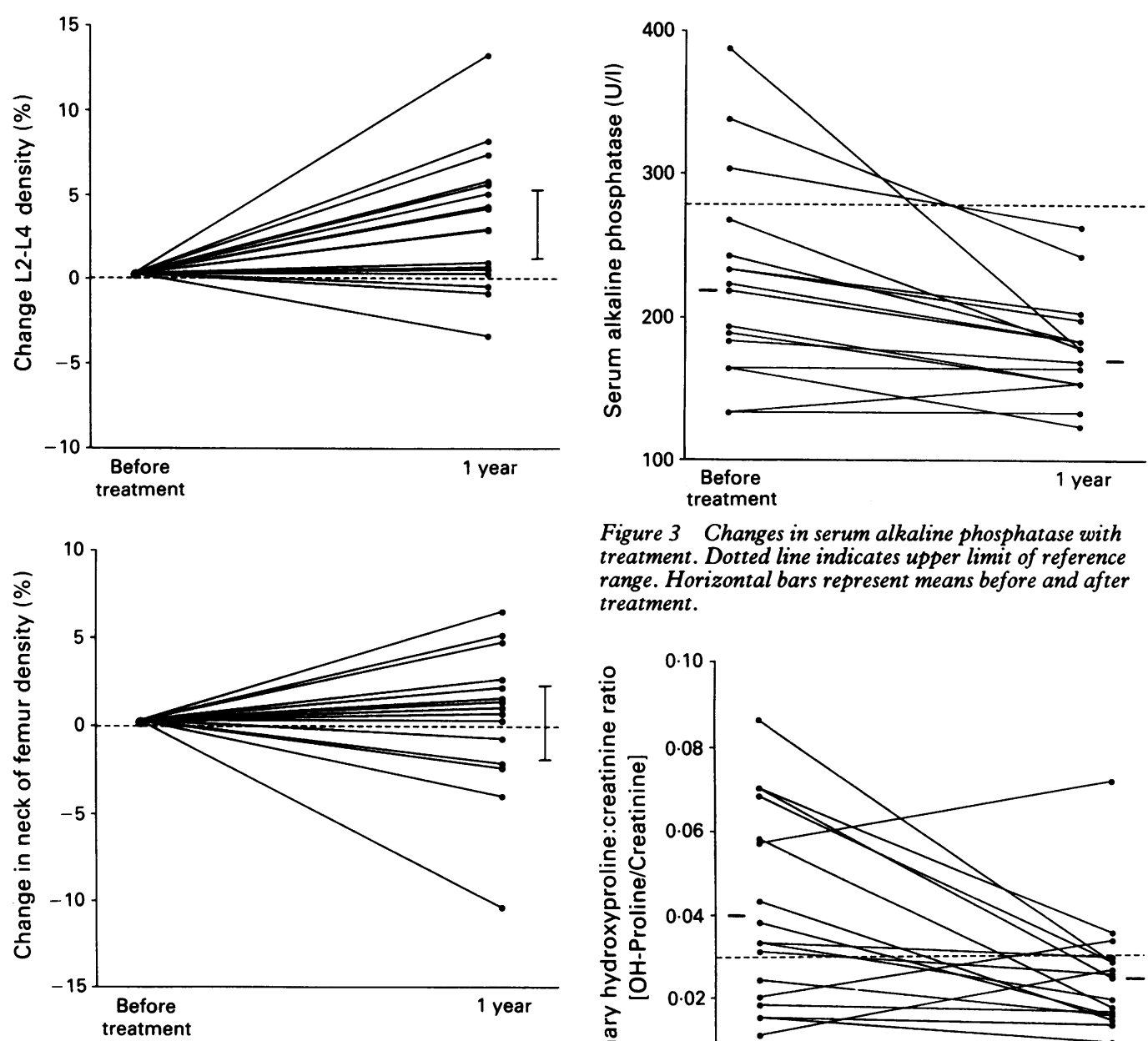

Concentrations of parathyroid hormone, $25(\mathrm{OH}) \mathrm{D} 3$, and 1,25 $(\mathrm{OH}) 2 \mathrm{D} 3$ before treatment were generally within the reference range-four patients had high parathyroid hormone values $(5.8,9.0,8.3,6.3 \mathrm{pmol} / \mathrm{l})$; none had subnormal $1,25(\mathrm{OH}) 2 \mathrm{D} 3$ concentrations. The mean (SEM) hydroxyproline:creatinine ratio before treatment was increased at 0.040 $(0.006)$, indicative of increased bone resorption. Serum alkaline phosphatase activity was within the reference range. There was a significant fall in both serum alkaline phosphatase activity (fig 3) with treatment from a mean (SEM) of 220 (16) U/1 to 174 (9) $U / 1$ (p < $0.002)$ and in the hydroxyproline : creatinine ratio from $0.040(0.006)$ to $0.024(0.003)$ (p < 0.01 ; fig 4). No significant correlation was evident either before or after treatment between alkaline phosphatase and the hydroxyproline:creatinine ratio.

Five patients developed pyrexia (range $37.5^{\circ} \mathrm{C}-38.8^{\circ} \mathrm{C}$ ) after treatment, which was symptomatic in four instances. This started about 24 hours after the infusion finished, lasted 12-18 hours and resolved spontaneously. This side effect is well recognised after treatment with intravenous pamidronate ${ }^{18}$ and only occurred after the first infusion. No change was noted in peak expiratory flow rate after infusion.

\section{Discussion}

On the basis of their bone densities and the
Figure 3 Changes in serum alkaline phosphatase with treatment. Dotted line indicates upper limit of reference range. Horizontal bars represent means before and after treatment.

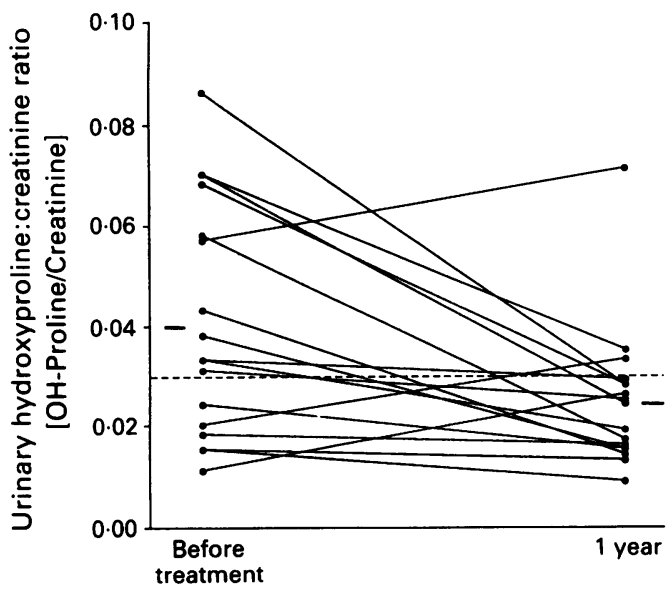

Figure 4 Changes in fasting urinary hydroxyproline: creatinine ratio with treatment. Dotted line indicates upper limit of reference range. Horizontal bars represent means before and after treatment.

presence of fractures before treatment these patients had appreciable osteoporosis. Treatment with intravenous pamidronate seemed effective in both reducing bone turnover and increasing bone density in patients with asthma and sarcoidosis treated with supraphysiological doses of corticosteroids.

Although data presented by Gennari ${ }^{19}$ suggested that bone loss with corticosteroids occurs only in the first six months of treatment, it is likely that bone loss continues with both age and continued treatment with corticosteroids. ${ }^{5}$ This view is supported by our data, which show an increased hydroxyproline: creatinine ratio (and therefore increased bone resorption) before treatment. Therefore, although this was an open, uncontrolled study, it is likely that the increased bone density and decreased bone turnover observed are of relevance.

We have previously shown that intermittent infusions of pamidronate are effective in the treatment of Paget's disease of bone. ${ }^{20} \mathrm{Al}$ though the dose of pamidronate administered in our present study was less than that for the treatment of Paget's disease, bone turnover in corticosteroid associated osteoporosis is increased to a lesser extent than in Paget's 
disease and it is likely therefore that a lower total dose of bisphosphonate would be effective. Furthermore we have shown that treatment with $30 \mathrm{mg}$ intravenous pamidronate is generally as effective in inhibiting osteoclastic bone resorption as higher doses in the treatment of cancer associated hypercalcaemia. ${ }^{21}$

To date, most studies with bisphosphonates for the treatment of osteoporosis have used oral routes of administration. Intravenous preparations have some theoretical advantages in that they overcome the poor oral absorption of these drugs $^{22}$ and they ensure that patient compliance with treatment can be accurately assessed. There has been considerable recent interest in the use of etidronate, given in a cyclic manner for two weeks at a time alternating with 11 weeks of calcium supplementation, in the treatment of postmenopausal osteoporosis. ${ }^{11} 12$ The use of intermittent infusions, as in our study, would be analogous to these cyclic regimens. As bisphosphonates, and pamidronate in particular, bind avidly to hydroxyapatite ${ }^{8}$ and therefore have a prolonged biological half life, the cyclic nature of the treatment regimen may not be necessary but rather the dose of bisphosphonate used should be low enough not to inhibit mineralisation, a known side effect of bisphosphonate treatment. ${ }^{23} \mathrm{With}$ intravenous treatment, however, an intermittent regimen is convenient for both the patient and the attending physician.

Little information is available on the use of bisphosphonates in corticosteroid associated osteoporosis. A previous study by Reid et al has, however, suggested that oral pamidronate administered continuously is effective in increasing bone density in corticosteroid associated osteoporosis ${ }^{24}$ and this increase in bone density can be maintained for at least two years. $^{25}$

The mean increase in L2-4 density of $3.4 \%$ is of a similar magnitude to that noted after etidronate treatment for one year in postmenopausal osteoporosis. ${ }^{112}$ The fact that there was no significant change in density of the neck of the femur suggests that the increase in L2-4 density was not achieved at the expense of a worsening of osteoporosis at the hip. This lack of effect on density of the neck of the femur was also noted in the study with etidronate in postmenopausal osteoporosis by Watts et al. ${ }^{12}$ The data from our study and from those using cyclic treatment with etidronate ${ }^{1112}$ would suggest that this treatment is likely to be most effective where osteopenia is severe. Intermittent intravenous pamidronate treatment, therefore, should probably be reserved for those patients who have already sustained an osteoporosis related fracture or who have densitometric evidence of osteopenia.

Although increases in bone density are important, the main end point in studies of this kind must be fracture rates. The fact that new fractures have continued to occur is not surprising as the bone density, although increased, is still probably below the fracture threshold. Obviously, in the absence of a control group, it is not possible to be certain of the relevance of these further fractures. Certainly in the studies of Storm et $a l^{11}$ and Watts et $a l^{12}$ no significant change in vertebral fracture rate was seen until at least 12 months into the study. This would also seem to be the case with pamidronate treatment. Further studies with larger numbers of patients and longer term follow up are required.

The mean hydroxyproline:creatinine ratio before treatment was high, implying increased rates of bone resorption. After treatment bone resorption was reduced and bone formation also seemed to be reduced although bone density increased. A possible explanation for this paradoxical effect is that resorption is inhibited and there is then a delay before local coupling mechanisms result in a decrease in bone formation and, therefore, bone formation goes on unopposed for some weeks. ${ }^{26}$

Several studies have suggested that vitamin D concentrations are low in corticosteroid associated osteoporosis. ${ }^{27}$ This was not the case in our study; in agreement with Hahn et $a l^{28} 1,25(\mathrm{OH}) 2 \mathrm{D} 3$ concentrations were normal or high. Similarly biochemical secondary hyperparathyroidism was found in only four of our patients, a lower number than might be expected. ${ }^{4}$ These results imply that the most important mechanism in the pathogenesis of this condition is the direct effect of corticosteroids on bone formation and resorption.

In summary, it seems that intermittent intravenous infusions of pamidronate are effective at reducing the increased bone turnover of corticosteroid associated osteoporosis. Furthermore this regimen can significantly increase bone density, which ultimately should lead to a decrease in the rate of fractures. Also this regimen seems to be well tolerated and acceptable to both the patients and the attending physicians. Long term controlled studies with this treatment are now indicated.

1 Adinoff AD, Hollister JR. Steroid induced fractures and bone loss in patients with asthma. $N$ Engl $J$ Med 1983;309:265-8.

2 Klein RG, Arnaud SB, Gallagher JC, DeLuca HF, Riggs BL. Intestinal calcium absorption in exogenous hypercortisolism. Role of 25 -hydroxyvitamin $D$ and corticosteroid dose. J Clin Invest 1977;60:253-9.

3 Sakakura M, Takebe K, Nakagawa S. Inhibition of leutinising hormone secretion induced by synthetic LRH by longing hormone secretion induced by synthetic LRH by longterm treatment with glucocorticoids in

4 Suzuki Y, Ichihawa Y, Saito E, Homma M. Importance of increased urinary calcium excretion in the development of secondary hyperparathyroidism of patients under secondary hyperparathyroidism of patients under glucocorticoid therapy. Metabolism 1983;32:151-6.

5 Lukert BP, Raisz LG. Glucocorticoid-induced osteoporosis: Pathogenesis and management. Ann Intern Med 1990;112:352-64.

6 Meunier PJ, Dempster DW, Edouard C, Chapuy MC, Arlot $M$, Charlson S. Bone histomorphometry in corticosteroidinduced osteoporosis in Cushing's syndrome. Adv Exp Med Biol 1984;171:191-200.

7 Dempster DW, Arlot MA, Meunier PJ. Mean wall thickness and formation periods of trabecular bone packets in corticosteroid-induced osteoporosis. Calcif Tissue Int 1983;35:410-7.

8 Fleisch H, Russell RGG, Francis MD. Diphosphonates inhibit hydroxyapatite dissolution in vitro and bone resorption in tissue culture and in vivo. Science 1969;165:1261-4

9 Ralston SH, Gardner MD, Dryburgh FJ, Jenkins AS, Cowan RA, Boyle IT. Comparison of aminohydroxypropylidene diphosphonate, mithramycin, and corticosteroids/calcitonin in treatment of cancerassociated hypercalcaemia. Lancet 1985;ii:907-10.

10 Smith R, Russell RGG, Bishop M. Diphosphonates and Paget's disease of bone. Lancet 1971;i:945-7.

11 Storm T, Thamsborg G, Steiniche T, Genant HK, Sorensen $\mathrm{OH}$. Effect of intermittent cyclical etidronate therapy on bone mass and fracture rate in women with postmeno- 
pausal osteoporosis. N Engl J Med 1990;322:1265-71.

12 Watts NB, Harris ST, Genant HK, Wasnich RD, Miller $\mathrm{PD}$, Jackson RD, et al. Intermitten cyclical etidronate treatment of postmenopausal osteoporosis $N$ Engl J Med 1990;323:73-9.

13 Russell .RGG Beard DG, Cameron EC, Douglas DL Forrest ARW, Guilland-Cutnming D, et al. Biochemical Farrest ARW, Guilland-Cumming D, et al. Biochemical
markers of bone turnover int. Paget's disease. Metabolic markers of bone turnover ip Paget's disease. Meta
Bone Disease and Related Res;oarch 1981;3:255-62.

14 Gouerde BC, Veenkamp FJN. Rputine assay of total urinary hydroxyproline based on resin-catalysed hydrolysis. Clin Chim Acta 1972ं;41:29-40.

15- Logue FC, Perry B; Chapman RS, Milne I, James K, Beastall GH. A two-site immunoradiometric assay for PTH (1-84) using N and C terminal specific monoclonal antibodies. Ann Clin Biochem 1991;28:160-6.

16 Ralston SH, Cowan RA, Robertson AG, Gardner MD, Boyle IT. Circulating vitamin D metabolites and hypercalcaemia of malignancy. Acta Endicrinol 1984;106: 556-63.

17 Mazess R, Collick B, Trempe J, Barden H, Hanson J. Performance evaluation of a dual-energy X-ray bone

18 Gallacher SJ, Ralston SH, Patel U, Boyle IT. Side effects of pamidronate. Lancet 1989;ii:42-3.

19 Gennari C. Glucocorticoids and bone. In: Peck WA, ed. Bone and Mineral Research/3. Amsterdam: Elsevier 1985:213-32.

20 Gallacher SJ, Boyce BF, Patel U, Jenkins A, Ralston SH, Boyle IT. Clinical experience with pamidronate in Paget's disease of bone. Ann Rheum Dis 1991;50:930-3.

21 Gallacher SJ, Ralston SH, Fraser WD, Dryburgh FJ, Cowan RA, Logue FC, Boyle IT. A comparison of low versus high dose pamidronate in cancer-associated hypercalcaemia. Bone Mineral 1991;15:249-56.

22 Fogelman I, Smith L, Mazess R, Wilson MA, Bevan JA. Absorption of oral diphosphonates in normal subjects. Clin Endocrinol 1986;24:57-62.

23 Boyce BF, Smith L, Fogelman I, Johnston E, Ralston S, Boyle IT. Focal osteomalacia due to low dose diphosphonate therapy in Paget's disease. Lancet 1984;1:821-4.

24 Reid IR, King AR, Alexander CJ, Ibbertson HK. Prevention of steroid-induced osteoporosis with (3-amino-1hydroxypropylidene)-1, 1-bisphosphonate (APD). Lancet 1988;i:143-6.

25 Reid IR, Heap SW, King AR, Ibbertson, HK. Two year follow up of bisphosphonate (APD) treatment in steroid osteoporosis Lancet 1988;ii:1144.

26 Parfitt AM. Morphologic basis of bone mineral measurements: transient and steady state effects of treatmeasurements: transient and steady state effects of treat-
ment in osteoporosis. Miner Electrolyte Metab 1980;4:273-87.

27 Chesney RW, Mazess RB, Hamstra AJ, DeLuca HF, O'Reagan S. Reduction of serum 1, 25 dihydroxyvitamin D3 in children receiving glucocorticoids. Lancet 1978;ii:1123-5.

28 Hahn TJ, Halstead LR, Baran TJ. Effects of short term glucocorticoid administration on intestinal calcium absorption and circulating vitamin $\mathrm{D}$ metabolite concentration in man. J Clin Endocrinol Metab 1981;52:111-5. 